\title{
Performance Study of Enhanced Non-Linear PID Control Applied on Brushless DC Motor
}

\author{
Mohamed. A. Shamseldin', M.A. Abdel Ghany ${ }^{2}$, A.M. Abdel Ghany ${ }^{3}$ \\ ${ }^{1}$ Department of Mechatronics Engineering, Future University in Egypt, Egypt \\ ${ }^{2}$ Department of Electrical Engineering, Egyptian Academy for Engineering and Advanced Technology, Egypt \\ ${ }^{3}$ Department of Electrical Engineering, Helwan University, Egypt
}

\begin{tabular}{l} 
Article Info \\
\hline Article history: \\
Received Oct 23, 2017 \\
Revised Nov 26, 2017 \\
Accepted Jan 26, 2018 \\
\hline Keyword: \\
Brushless DC (BLDC) motor \\
Fuzzy logic control \\
Fractional order PID control \\
Genetic algorithm (GA) \\
Non linear PID control \\
\end{tabular}

\begin{abstract}
This paper presents an enhanced nonlinear PID (NPID) controller to follow a preselected speed profile of brushless DC motor drive system. This objective should be achieved regardless the parameter variations, and external disturbances. The performance of enhanced NPID controller will be investigated by comparing it with linear PID control and fractional order PID (FOPID) control. These controllers are tested for both speed regulation and speed tracking. The optimal parameters values of each control technique were obtained using Genetic Algorithm (GA) based on a certain cost function. Results shows that the proposed NPID controller has better performance among other techniques (PID and FOPID controller).
\end{abstract}

Copyright $(0) 2018$ Institute of Advanced Engineering and Science. All rights reserved.

Corresponding Author:

A.M. Abdel Ghany,

Departement of Electrical and Computer Engineering,

Helwan University, Egypt

Email: ghanyghany@ hotmail.com

\section{INTRODUCTION}

Recently Brushless DC (BLDC) motors have been replaced conventional DC motors in many industrial applications such as steel rolling mills, electric trains, electric automotive, aviation and robotics [1]. This because BLDC motor has many advantages compared to their DC counter-part such as long operating life, high dynamic response, high efficiency and higher speed range [2]. BLDC motor is driven by DC voltage source but current commutation is done by solid-state switches [3]. The commutation instants are determined by the rotor position which is detected by position sensors or by using sensorless techniques [4].

Proportional-Integral-Derivative (PID) controllers have been used for several decades in industries for process control applications [5]. The reason for their wide popularity lies in the simplicity of design and the good performance including the low percentage overshoot and the small settling time for slow process plants [6]. The performance of PID controllers can be further improved by using of the fractional order derivatives and integrals.

The fractional order PID controllers include two more parameters where the $(\lambda)$ and $(\mu)$ are the power of (s) in integral and derivative actions respectively beside the three well known parameters proportional $\left(K_{P}\right)$, integral $\left(K_{I}\right)$ and derivative $\left(K_{D}\right)$ parameters [7]. These additional parameters increase the flexibility and robustness of this controller, and hence enhancing its dynamic performance compared to its integer counterpart [8],[9].

Both the PID and FOPID controller still have fixed gains which are not enough to deal with high complicated dynamic systems [10],[11]. It is known that most of dynamic systems has nonlinear behavior so, the linear PID control is not adequate to achieve high performance. As example, the BLDC motor consists of nonlinear components such as rectifier circuit and six step inverter [12]. This study presents a new proposed 
nonlinear PID (NPID) controller which contain on nonlinear gains incorporated with the fixed gains of PID controller [12]. These nonlinear gains enjoy the advantage of high initial gain to attain a fast dynamic response, followed by a low gain to prevent an oscillatory behavior [13].

The performance of the PID, FOPID and NPID controller are highly affected by selecting its parameters to meet the desired performance of user for a given process plant.

It has been reported in several of researches that use the optimization techniques to find the proper parameters of controller is very useful and reliable compared to traditional techniques (Ziegler-Nichols method). There are different types of optimization techniques such as Genetic Algorithm (GA), particle swarm and ant colony [2]. In this paper, the GA will be used to find the proper controller parameters of each control technique according to a certain cost function.

The main contribution of paper is developing a new technique for nonlinear PID (enhanced NPID) control and compares it with other control techniques (PID and FOPID control) to confirm the precedence. The paper is organized as follows: Section II presents the dynamic modeling of BLDC motor drive system. The control techniques are included in Section III. Section IV provides the simulation results. Finally, Section V concludes.

\section{DYNAMIC MODEL OF BLDC MOTOR}

In order to study the different proposed control techniques on a BLDC motor, it is essential to introduce the used dynamic model of this motor The transfer-function based mathematical models are widely used in automatic control fields. Some control design and analysis methods, such as the root-locus method and the frequency-response method, are also developed based on the system transfer function

The transfer function of the BLDC motor at no load may be written as follows [14],[5]:

$\frac{\omega(S)}{U_{d}(S)}=\frac{\frac{1}{K_{e}}}{\left(t_{m} \cdot t_{e}\right) \cdot S^{2}+t_{m} \cdot S+1}$

$t_{m}=\frac{3 R J}{K_{e} K_{t}}$

$t e=\frac{L}{3 R}$

Where $U_{d}$ is the DC bus voltage, $t_{m}$ is the mechanical time constant, $t_{e}$ is the electrical time constant, $R$ and $\mathrm{L}$ are the terminal phase to phase resistance and inductance, $\mathrm{J}$ is the rotor moment of inertia, $\omega$ is the rotor speed, $K_{e}$ is the coefficient of phase back-EMF constant, and $K_{T}$ is the coefficient of phase torque constant.

Figure 1 shows the block diagram of the proposed drive system. It consists of a BLDC motor equipped with a hall-effect sensor which determines the rotor position and sends a feedback signal to the control unit. The control unit consists of a microcontroller and a driving circuit. The microcontroller uses the feedback signals of the motor position and delivers the control pulses to the driving circuit. Then, the driving circuit isolates between the control and power circuit as well as drive the proper pulses for the inverter power circuit. The used inverter type is a voltage source inverter. It converts the DC supply to a suitable one in order to drive the BLDC. The DC supply is achieved by using an uncontrolled rectifier followed by a DC link capacitor [15].

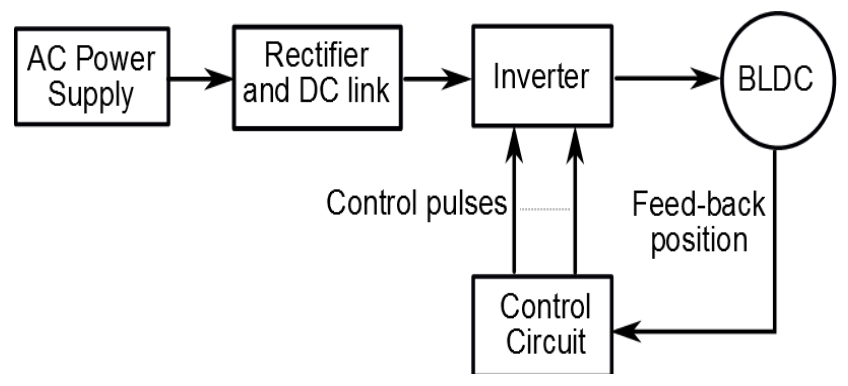

Figure 1. Brushless DC motor drive system

The parameters of the BLDC motor are listed in Table 1. 
Table 1. The BLDC Motor Parameters.

\begin{tabular}{|c|c|c|c|}
\hline Rating & Symbol & Value & Units \\
\hline DC resistance & $\mathrm{R}$ & 0.57 & $\Omega$ \\
\hline Inductance & $\mathrm{L}$ & 1.5 & $\mathrm{mH}$ \\
\hline Torque constant & $K_{T}$ & 0.082 & N.m/A \\
\hline No. of Poles & $\mathrm{P}$ & 4 & \\
\hline Rated torque & $T_{p}$ & 0.42 & N.m \\
\hline Rated Voltage & V & 36 & V \\
\hline Rotor Inertia & $\mathrm{J}$ & $23 e^{-6}$ & Kg.m2 \\
\hline Friction coefficient & $B_{v}$ & 0.0000735 & N.M.S \\
\hline Rated Speed & $\omega$ & 4000 & RPM \\
\hline Rated current & I & 5 & A \\
\hline
\end{tabular}

Figure 2 demonstrates the open loop response of BLDC motor drive system model. It can be noted that at time $0.1 \mathrm{sec}$ the BLDC motor exposed to sudden load correspond $50 \%$ of rated torque, the rotor speed will be reduced to 3200 RPM. Figure 3 shows the corresponding phase current of BLDC motor. It can clear that the phase current will be increased at time $0.1 \mathrm{sec}$ to $\pm 2.5 \mathrm{~A}$.

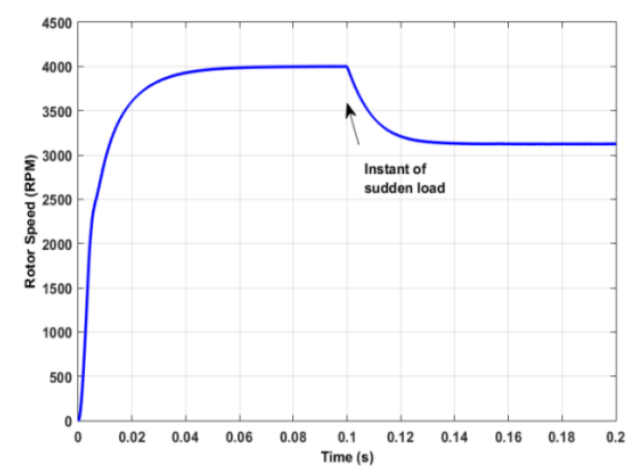

Figure 2. Open loop response of BLDC motor drive system model

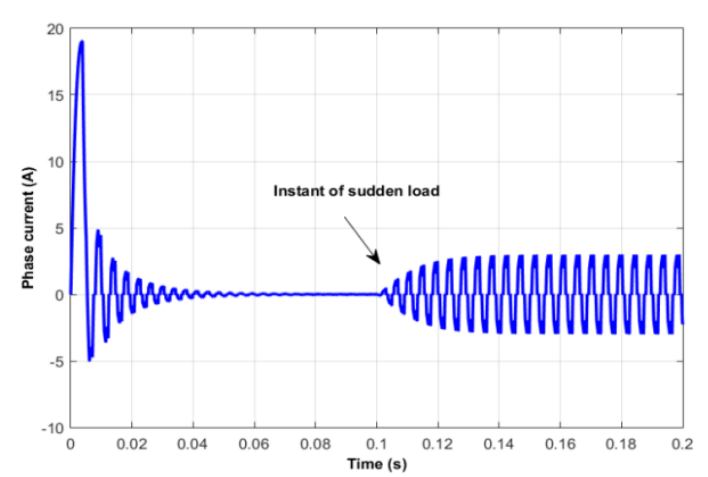

Figure 3. The corresponding phase current of BLDC motor model

\section{CONTROL TECHNIQUES}

This section illustrates the theory of three different control techniques. The first technique is the conventional PID control while, the second technique is the fractional order PID control. The third technique is the nonlinear PID control. The parameters of each control technique were obtained by GA optimization technique based on a certain cost function.

\subsection{PID Control}

Proportional-integral-derivative (PID) controllers have been the most famous and the most commonly used industrial controllers in the previous years. The reputation and widespread use of PID controllers are attributed primarily to their simplicity and performance characteristics [16]. PID controllers have been applied for control of various dynamical systems ranged from industrial process to complicated dynamics such as ship and aircraft [17].

The transfer function of the PID controller is $K(s)=K_{P}+\frac{K_{i}}{s}+K_{d} s$. Where $K_{p}, K_{i}, k_{d}$ are proportional, integral and differential gains respectively. The task of each part of a PID controller can be described as follows, the proportional part decreases the error responses of the system to disturbances, the integral part rejects the steady-state error, and finally the derivative part dampens the dynamic response and improves the system stability. The problem in the PID controller is to select the proper three parameters to be suitable for the controlled plant. There are different methods to find the parameters of PID controller such as try and error and Ziegler-Nichols method but, most of these methods are rough roads. In this paper the GA optimization technique will be used to obtain the optimal values of PID controller parameters based on the cost function as shown in (4). 
$f=\frac{1}{\left(1-e^{-\beta}\right)\left(M_{p}+e_{s S}\right)+e^{-\beta}\left(t_{s}-t_{r}\right)}$

This cost function can satisfy the designer demand using the weighting factor value $(\beta)$. The factor is set larger than 0.7 to decrease over shoot and steady-state error. If this factor is set smaller than 0.7 the rise time and settling time will be decreased [18].

Matlab genetic algorithm toolbox is used to tune the PID controller parameters according to the previous objective function. The first and the most critical step is to convert the problem into suitable GA chromosomes and then construct the population. Some works recommend 20 to 100 chromosomes in one population. The higher the chromosomes number, the better chance to get the optimal results. However, using more chromosomes requires more execution time. In this paper, it is desired to use 80 chromosomes in each generation.

Each chromosome comprises of three parameters, i.e. $K_{P}, K_{I}, K_{D}$ with value bounds varied depend on the used objective function. In order to reach to accurate values for the PID parameters, the initial values of $K_{P}, K_{I}, K_{D}$ are determined using Ziegler-Nichols rule. The population in each generation is represented by $80 \times 4$ population (P) matrix as given by (3), depends on the chromosomes number in population, where each row represents a one chromosome that comprise $K_{P}, K_{i}, K_{d}$ values and the last column is added to accommodate fitness values $(\mathrm{F})$ of corresponding chromosomes.

$P_{1}=\left[\begin{array}{cccc}K_{p 1} & K_{i 1} & K_{d 1} & F_{1} \\ K_{p 2} & K_{i 2} & K_{d 2} & F_{2} \\ . . & . . & . . & . . \\ . . & . . & . . & . . \\ K_{p n} & K_{i n} & K_{d n} & F n\end{array}\right]$

Where $\mathrm{n}$ is the number of chromosomes.

\subsection{FOPID Control}

The most common form of a fractional order PID controller is the $\mathrm{PI}^{\lambda} \mathrm{D}^{\mu}$, including an integrator of order $\lambda$ and a differentiator of order $\mu$ as demonstrated in Figure 4 where $\mu$ and $\lambda$ can be any real numbers. The controller transfer function has the form [19]:

$$
G_{c}=\frac{U(s)}{E(s)}=k_{p}+k_{i} \frac{1}{s^{\lambda}}+k_{d} s^{\mu},(\lambda, \mu>0)
$$

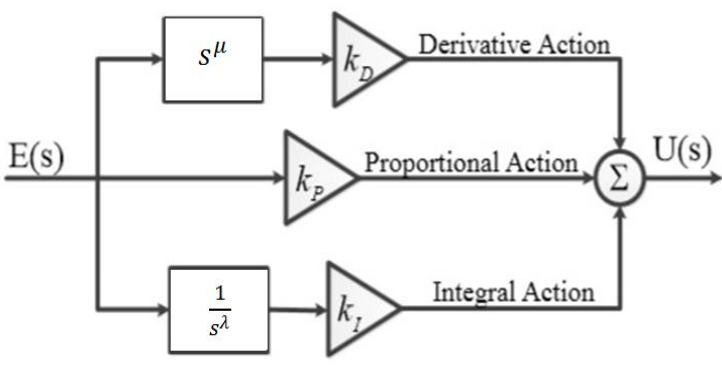

Figure 4. FOPID controller block diagram

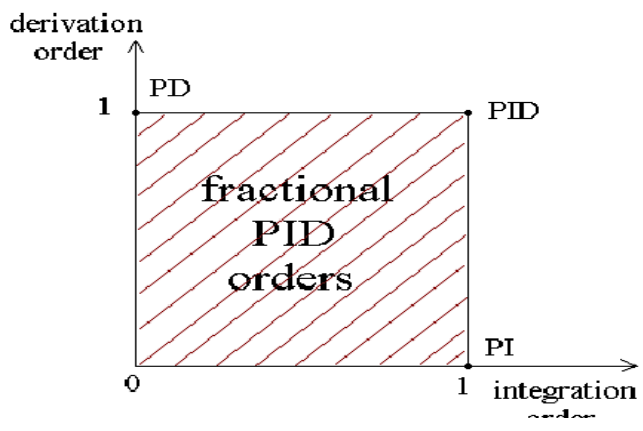

Figure 5. Expanding from Point to Plane

Conventional PID controller can be obtained by adjusting $\lambda=1$ and $\mu=1$. So, the conventional PID controller is special case from the FOPID controller which enlarges the PID control from point to plane as shown in Figure 5. This extension provides us much more flexibility and reliability and provides a chance to enhance the performance of control system and that is through the two more parameters of FOPID. Moreover, this improves the robustness of the system against any unexpected variables and makes it more stable where by adjusting the two more parameters of FOPID can compensate any disturbances in system . But, now the task of the designer selects the five parameters instead of three parameters which will be more challenging for achieving a certain performance [19]. 
In this paper, the FOPID control parameters will be adjusted using GA optimization based on the previous cost function. The first step is to encrypt the problem into appropriate GA chromosomes. Each chromosome includes five parameters, i.e. $K_{P}, K_{I}, K_{D}, \lambda$ and $\mu$ with value bounds varied depend on the used cost function. The initial values of $K_{P}, K_{I}, K_{D}, \lambda$ and $\mu$ are obtained using Ziegler-Nichols rule to reach accurate values. The population in each generation is represented by $80 \times 6$ population $(\mathrm{P} 2)$ matrix as given by (4), depends on the chromosomes number in population, where each row represents a one chromosome that comprise $K_{P}, K_{i}, K_{d}, \lambda$ and $\mu$ values and the last column is added to accommodate fitness values (F) of corresponding chromosomes.

$\mathrm{P} 2=\left[\begin{array}{cccccc}K_{p 1} & K_{i 1} & K_{d 1} & \lambda_{1} & \mu_{1} & F_{1} \\ K_{p 2} & K_{i 2} & K_{d 2} & \lambda_{2} & \mu_{2} & F_{2} \\ . . & . . & . . & . . & . . & . . \\ . . & . . & . . & . . & . . & . . \\ K_{p n} & K_{i n} & K_{d n} & \lambda_{n} & \mu_{n} & F n\end{array}\right]$

Where $\mathrm{n}$ is the number of chromosomes.

\subsection{NPID Control}

For controlling a nominal physical process, the demands for high-performance control with different operating conditions or environmental parameters are often beyond the capabilities of simple PID controllers. In order to improve the performance of linear PID controllers, many techniques have been established to increase the adaptability and robustness by adopting the self-tuning method, general predictive control, neural networks strategy and fuzzy logic, and other methods [13].

Among these techniques, nonlinear PID (NPID) control is presented as one of the most effective and simple method for industrial applications. The nonlinear PID (NPID) control has found in form two broad categories of applications [10]. The first category particular to nonlinear systems, where NPID control is used to accommodate the nonlinearity while, the second category deals with linear systems, where NPID control is used to obtain performance not realizable by a linear PID control, such as increased damping, reduced rise time for step or rapid inputs, improved tracking accuracy, and friction compensation.

The NPID controllers have the advantage of high initial gain to achieve a fast response, followed by a low gain to avoid an oscillatory behavior. In this study, a performance enhancement to the conventional linear PID controller is proposed by combining a sector-bounded nonlinear gain into a linear fixed gain PID control architecture [12].

In this paper, the proposed enhanced nonlinear PID (NPID) controller consists of two parts. The first part is a sector bounded nonlinear gain $K_{n}(e)$ while, the second part is a linear fixed-gain PID controller (Kp, $\mathrm{Ki}$ and $\mathrm{Kd})$. The nonlinear gain $K_{n}(e)$ is a sector-bounded function of the error e $(\mathrm{t})$. the previous researches have been made where the nonlinear gain $K_{n}(e)$ has a one scalar value.

In this paper, The $K_{n}(e)$ acts as a row vector can expressed as $K_{n}(e)=\left[\begin{array}{llll}K_{n 1}(e) & K_{n 2}(e) & K_{n 3}(e)\end{array}\right]$ which will be enhanced the NPID controller.

The proposed form of NPID control can be described as follows.

$u(t)=K_{p}\left[K_{n 1}(e) \cdot e(t)\right]+K_{i} \int_{0}^{t}\left[K_{n 2}(e) \cdot e(t)\right] d t+K_{d}\left[K_{n 3}(e) \cdot \frac{d e(t)}{d t}\right]$

Where $K_{n 1}(e), K_{n 2}(e)$ and $K_{n 3}(e)$ are nonlinear gains. The nonlinear gains represent any general nonlinear function of the error e which is bounded in the sector $0<K_{n}(e)<K_{n}(e) \max$. There is a broad range of options available for the nonlinear gain $K_{n}(e)$. One simple form of the nonlinear gain function can be described as.

$K_{n i}(e)=\operatorname{ch}\left(w_{i} e\right)=\frac{\exp \left(w_{i} e\right)+\exp \left(-w_{i} e\right)}{2}$

Where $i=1,2,3$.

$e=\left\{\begin{array}{ll}e & |e| \leq e_{\max } \\ e_{\max } \operatorname{sgn}(e) & |e|>e_{\max }\end{array}\right\}$ 
Where $w_{i}$ and $e_{\text {max }}$ are user-defined positive constants. The nonlinear gain $K_{n}(e)$ is lower bounded by $K_{n}(e) \min =1$ when $\mathrm{e}=0$, and upper-bounded by $K_{n}(e) \max =\operatorname{ch}\left(w_{i} e_{\max }\right)$. Therefore, $e_{\max }$ stand for the range of variation, and $w_{i}$ describes the rate of variation of $K_{n}(e)$.

Matlab genetic algorithm toolbox is used to adjust the NPID controller parameters according to the earlier cost function. The population in each generation is represented by $80 \times 7$ population (P3) matrix as given by (8). Each row represents a one chromosome that include $K_{P}, K_{i}, K_{d}, w_{1}, w_{2}$ and $w_{3}$ values and the last column is added to adapt fitness values (F) of corresponding chromosomes.

$P_{3}=\left[\begin{array}{ccccccc}K_{p 1} & K_{i 1} & K_{d 1} & w_{11} & w_{21} & w_{31} & F_{1} \\ K_{p 2} & K_{i 2} & K_{d 2} & w_{12} & w_{22} & w_{32} & F_{2} \\ . . & . . & . . & . . & . . & . . & . . \\ . . & . . & . . & . . & . . & . . & . . \\ K_{p n} & K_{i n} & K_{d n} & w_{1 n} & w_{1 n} & w_{3 n} & F n\end{array}\right]$

Where $\mathrm{n}$ is the number of chromosomes.

\section{SIMULATION RESULTS}

This section presents investigates the performance of each control technique where several of investigations will be applied on the BLDC motor such as speed regulation, sudden load, speed tracking and continuous variable load.

Figure 6 demonstrates the speed response of Both the NPID control with scalar and vector nonlinear gain. It is obvious that the rotor of BLDC motor was exposed to sudden load by half rated torque at time 0.1 sec. Also, it can be noted that the performance of the NPID controller with vector nonlinear gain has faster response than other kind of NPID control. Moreover, it can absorb the disorder rapidly at time $0.1 \mathrm{sec}$.

The rest of tests will be performed by using the NPID control with a vector value and will be compared with GA-PID control and FOPID control.

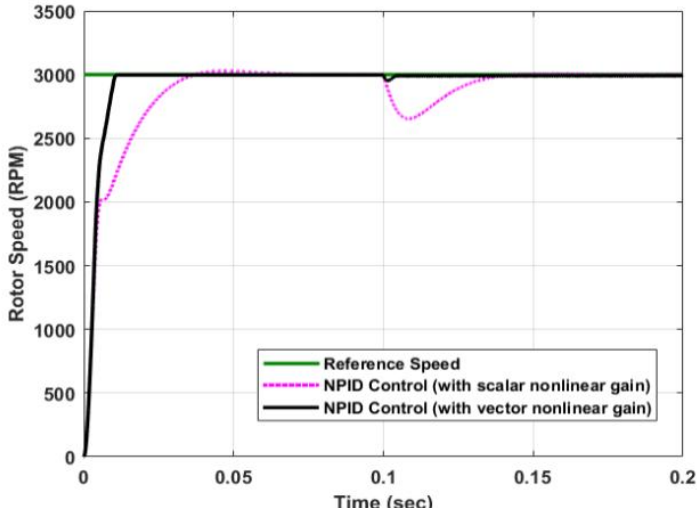

Figure 6. Speed response of control techniques during the speed regulation

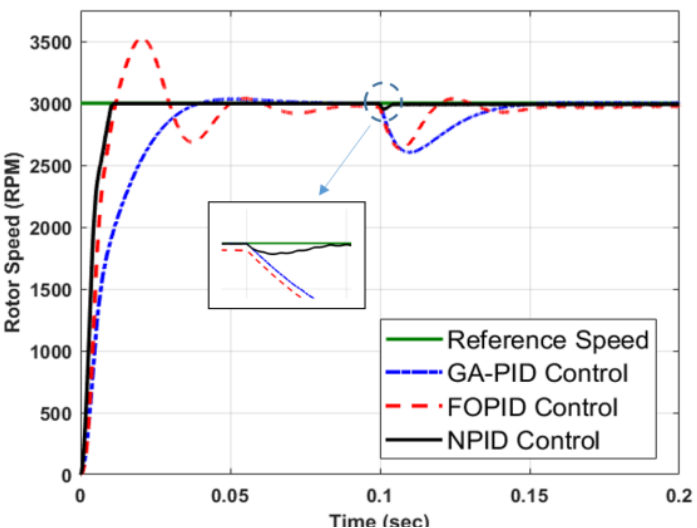

Figure 7. Speed response of control techniques during the speed regulation

Figure 8 demonstrates the corresponding DC supply current of each control technique. It can be noted that the NPID controller has high starting current compared to other techniques. In case of sudden load at time $0.1 \mathrm{sec}$, the DC supply current of NPID control will be raised rapidly among other techniques to can accommodate the disturbance in a short time. 


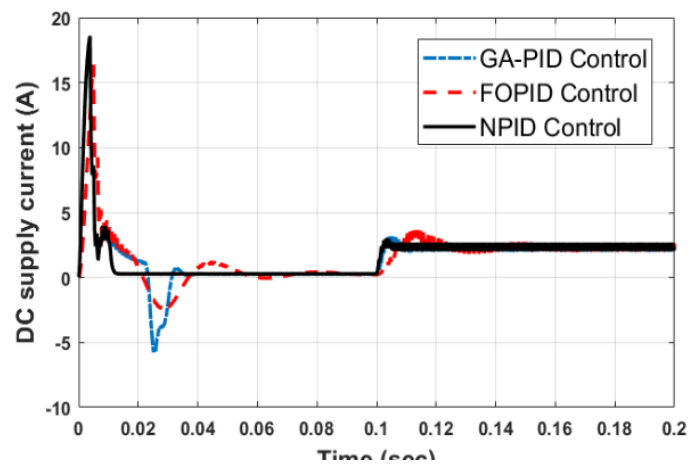

Figure 8. The corresponding DC supply of each control technique during the speed regulation

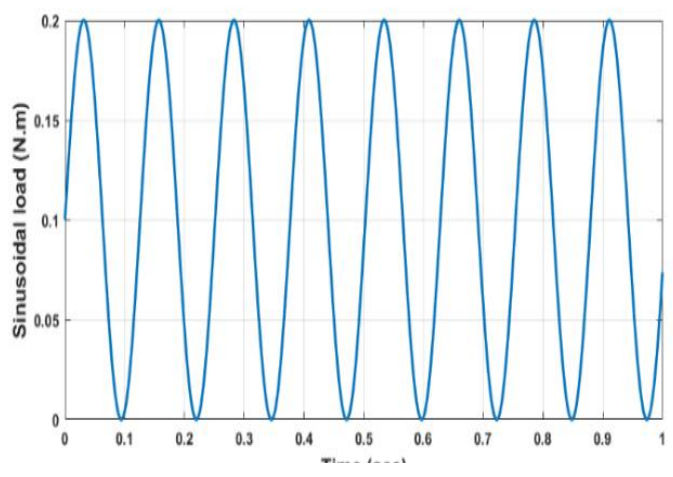

Figure 9. Sinusoidal load torque that exposed to the BLDC motor through the simulation

Table 2 summarizes and give us accurate comparison of each control technique performance Figure 6 and 7. It is obvious that the dynamic response of GA-PID control is very slow compared to other techniques. Also, the rise time of FOPID control close to the rise time of NPID control (with vector nonlinear gain) but, it suffers from high overshoot. Moreover, the NPID control (with vector nonlinear gain) has the minimum rise and settling time and no overshoot.

Table 2. Control Techniques Performance

\begin{tabular}{cccc}
\hline Controller Method & Rise Time (sec) & Settling Time (sec) & Max. Overshoot \% \\
\hline GA-PID Control & 0.0219 & 0.0342 & 1.1107 \\
FOPID Control & 0.0071 & 0.0756 & 18.13 \\
NPID control (with scalar nonlinear gain) & 0.0195 & 0.1301 & 0.9382 \\
NPID Control (with vector nonlinear gain) & 0.0067 & 0.0099 & 0.0001 \\
\hline
\end{tabular}

Sometimes, the BLDC motor exposed to sinusoidal load when used as actuator in robotics applications because of the change of links inertia with robot movement. So, the BLDC motor needs robust control to can regulate the speed of BLDC motor through the continuous load change which can expressed as sinusoidal function has a peak 0.2 N.m as shown in Figure 9.

Figure 10 illustrates the speed response of each control technique through the continuous load change. It is noted that the rotor speed of BLDC motor oscillated about the reference speed. Both the GAPID control and FOPID control have high deviation about reference speed while, the enhanced NPID control can eliminate the continuous disturbance without high deviation about the reference speed.

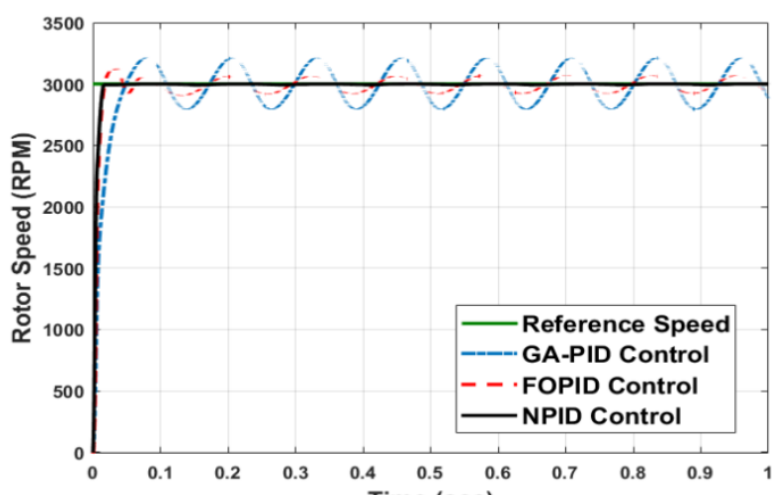

Figure 10. Performance of control techniques through sinusoidal load

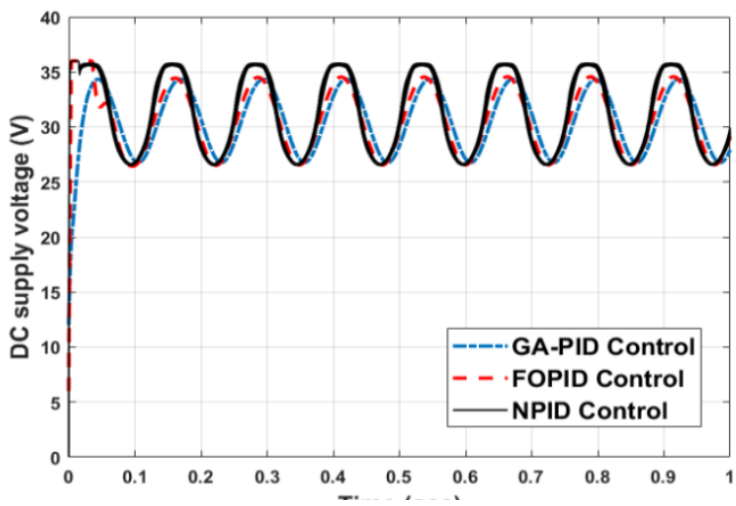

Figure 11. The corresponding control techniques output through sinusoidal load 
Table 3 demonstrates the deviation values about the reference speed of each control technique. It is noted that the GA-PID control and FOPID control have high deviation while, the NPID control has very small deviation about the reference speed.

Table 3. Control Techniques Deviation.

\begin{tabular}{ccc}
\hline Controller Method & Deviation (RPM) & Deviation (\%) \\
\hline GA-PID Control & \pm 220 & $7.34 \%$ \\
FOPID Control & \pm 75 & $2.5 \%$ \\
NPID Control & \pm 5 & $0.17 \%$ \\
\hline
\end{tabular}

The reference speed of BLDC motor in some industrial applications is not constant and need to change continuously such as robotics and electric automotive. So, Figure 12 shows the response of each control technique at different commands of reference speed with constant load correspond $10 \%$ of rated torque. We note that NPID control can track the reference speed faster than other techniques.

Figure 13 illustrates the corresponding DC supply current of each controller technique. It is clear that the NPID control has high starting current with each change in reference speed compared to other techniques.

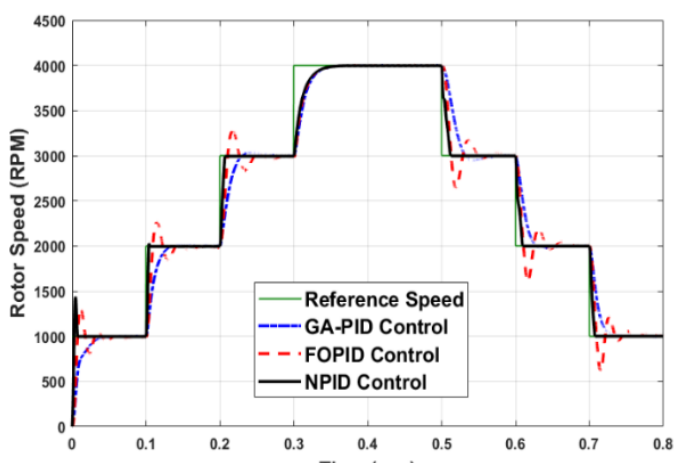

Figure 12. Speed response of control techniques at different commands of reference speed

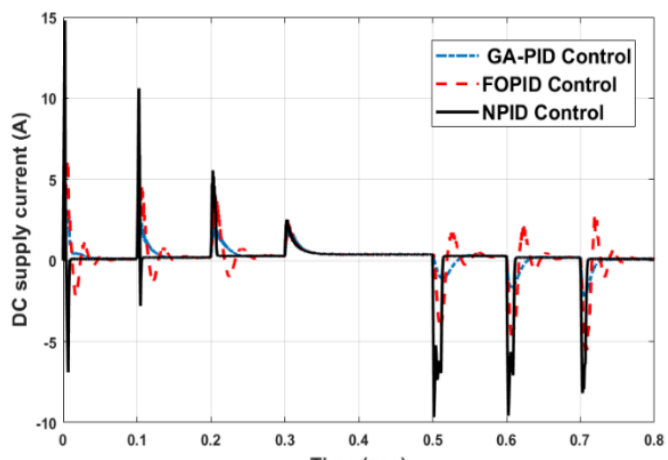

Figure 13. The corresponding DC supply current of control techniques at different commands of reference speed

\section{CONCLUSION}

In this paper, an enhanced nonlinear PID (NPID) controller is proposed to improve the performance of BLDC motor and track a preselected speed/position profile regardless the parameter variations and sudden load. To ensure the robustness of NPID control two different techniques were compared with it. The first technique is the conventional PID control while the second technique is the fractional order PID control. The genetic algorithm optimization technique is used to obtain the proper parameters of each control technique. Simulation results illustrate that the proposed NPID controller can accommodate the different types of disturbance rapidly and has faster response compared to other control techniques.

\section{ACKNOWLEDGEMENTS}

We would like to express our deepest thanks to: Prof. A.M. Abdel Ghany for his guidance to this field.

\section{REFERENCES}

[1] M. Irfan, M. Effendy, N. Alif, S. Lailis, I. Pakaya, and A. Faruq, "Performance Comparison of Fuzzy Logic and Proportional-integral for an Electronic Load Controller,” Int. J. Power Electron. Drive Syst., vol. 8, no. 3, pp. 1176 1183, 2017.

[2] R. R. Navatakke and J. Bichagatti, "Optimal PID control of a brushless DC motor using PSOtechnique," vol. 10, no. 3, pp. 13-17, 2015.

[3] A. A. El-samahy and M. A. Shamseldin, "Brushless DC motor tracking control using self-tuning fuzzy PID control and model reference adaptive control," Ain Shams Eng. J., 2016. 
[4] C. S. Vishnu and R. M. Francis, "Speed Control of BLDC Motor by Using Tuned Linear Quadratic Regulator," Int. J. Sci. Eng. Res., vol. 3, no. 8, pp. 36-40, 2015.

[5] M. A. A. Ghany, M. A. Shamseldin, and A. M. A. Ghany, "A Novel Fuzzy Self Tuning Technique of Single Neuron PID Controller for Brushless DC Motor,” Int. J. Power Electron. Drive Syst., vol. 8, no. 4, pp. 1705-1713, 2017.

[6] L. Mohan, M. Scholar, and P. Electronics, "Comparison of PI and Adaptive Fuzzy PID Controllers for Speed Control of BLDC Motor," internaional J. Innov. Res. Electr. Electron. Instrum. Control Eng., vol. 2, no. 2, pp. 1050-1054, 2014.

[7] M. A. Shamseldin, A. A. El-samahy, and A. M. A. Ghany, "Different Techniques of Self-Tuning FOPID Control for Brushless DC Motor," in MEPCON, 2016.

[8] M. R. Dastranj, M. Rouhani, and A. Hajipoor, "Design of Optimal Fractional Order PID Controller Using PSO Algorithm," Int. J. Comput. Theory Eng., vol. 4, no. 3, pp. 429-432, 2012.

[9] A. Rastogi and P. Tiwari, "Optimal Tuning of Fractional Order PID Controller for DC Motor Speed Control Using Particle Swarm Optimization,” Int. J. Soft Comput. Eng., vol. 3, no. 2, pp. 150-157, 2013.

[10] Y. Ren, Z. Li, and F. Zhang, “A New Nonlinear PID Controller and its Parameter Design,” Int. J. Comput. Electr. Autom. Control Inf. Eng., vol. 4, no. 12, pp. 1950-1955, 2010.

[11] D. Vanitha and M. Rathinakumar, "Fractional Order PID Controlled PV Buck Boost Converter with Coupled Inductor," Int. J. Power Electron. Drive Syst., vol. 8, no. 3, pp. 1401-1407, 2017.

[12] D. V. L. N. Sastry and M. S. R. Naidu, "An Implementation of Different Non Linear PID Controllers on a Single Tank level Control using Matlab,” Int. J. Comput. Appl., vol. 54, no. 1, pp. 6-8, 2012.

[13] Y. X. Su, D. Sun, and B. Y. Duan, "Design of an enhanced nonlinear PID controller," Mechatronics, vol. 15, pp. 1005-1024, 2005.

[14] O. J. Oguntoyinbo, "PID CONTROL OF BRUSHLESS DC MOTOR AND ROBOT TRAJECTORY PLANNING AND SIMULATION WITH," 2009.

[15] Z. Ho, C. Uang, and P. Wang, "Extracting DC bus current information for optimal phase correction and current ripple in sensorless brushless DC motor drive *," J. Zhejiang Univ. C (Computers Electron., vol. 15, no. 4, pp. 312 320, 2014.

[16] M. Drive, "Modeling and Analysis of PI Controller Based Speed Control of Brushless DC Motor Drive," IJESRT, vol. 2, no. 9, pp. 7-12, 2013.

[17] J. Poovarasan, R. Kayalvizhi, and R. K. Pongiannan, "Design of Fractional Order PID controller for a CSTR process,” Int. Ref. J. Eng. Sci., vol. 3, no. 1, pp. 8-14, 2014.

[18] M. A. Shamseldin and A. A. El-samahy, "Speed Control of BLDC Motor By Using PID Control and Self-tuning Fuzzy PID Controller," in 15th International Workshop on Research and Education in Mechatronics (REM), 2014.

[19] A. A. Kesarkar and N. Selvaganesan, "Systems Science \& Control Engineering Tuning of optimal fractional-order PID controller using an artificial bee colony algorithm," Syst. Sci. Control Eng., vol. 2583, no. November, 2015.

\section{BIOGRAPHIES OF AUTHORS}

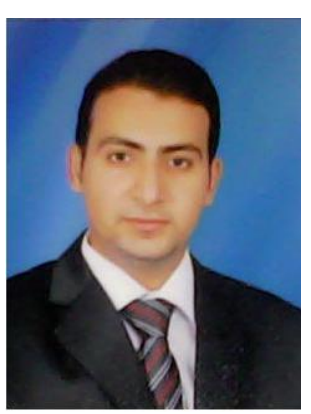

Eng. Mohamed.A. Shamseldin born in Cairo, Egypt, on October 1, 1987. He received the B.Sc. degree in mechatronics engineering in 2010 from faculty of engineering at Helwan, Helwan University, Cairo, Egypt. On December 2012, he received his work in faculty of engineering and technology at Future University in Egypt as an instructor in Mechatronics Engineering Department. M.Sc. in system automation and engineering management (2012 to 2016) from, Helwan University, Cairo, Egypt. His research activity includes studying Artificial Intelligent techniques, electrical machines speed control and robotics control.

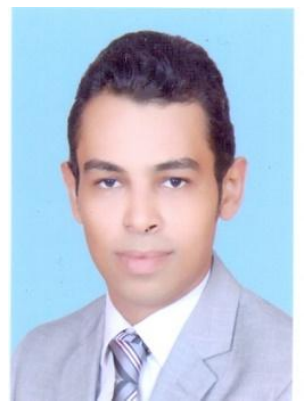

Eng. M A. Abdel Ghany was born in Cairo 22thJuly1988. He received his B. Sc from Higher Technological Institute (Tenth of Ramadan City) 2011, Diploma and M.Sc. in Automatic Control (2012 to 2014) from, Helwan University, Cairo, Egypt. From 20/6/2015 until now he worked as an Assistant Lecturer at Faculty of Computer science Nahda University, Bani Sweif City. Now he is Ph. D student in Automatic Control branch in Helwan University, Cairo, Egypt. Registered for Ph.D. (Automatic Control) in Electrical Engineering Department, Faculty of Engineering, Helwan University, Egypt. 


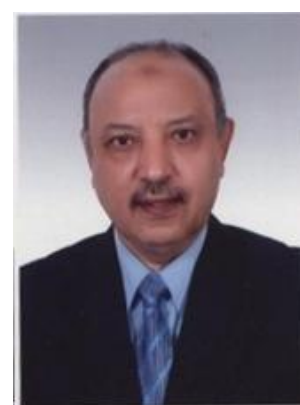

Dr. A .M. Abdel Ghany was born in Cairo. He received his B.Sc. and M.Sc. degrees in 1980 and 1987 from the Electrical Power System and Machines department, Helwan University , Cairo, Egypt. From 1989 to 1994, he got his Ph.D. in Computer Controlled Systems from the Institute of Control and Systems Engineering, Technical University of Wroclaw Poland. From 1994 to 1999, he worked as an assistant professor at the department of Electrical Machines and Power System, Helwan University, Cairo Egypt. In 2002, he was promoted to Associate Professor at the Department of Electrical Power Systems and Machines Department, University of Helwan, Cairo, Egypt. Currently, he was a lecturer at the Electrical Technology department, College of Technology at Al-Baha, Al-Baha, KSA. Dr. Abdel Ghany shared in the Economical Lighting of Helwan industrial plant as a part of the Supreme Council of Egyptian Universities Projects. He authored more than 114 papers in control and analysis of Power Systems. 